\title{
REUSE IN PRACTICE: THE UK'S CAR AND CLOTHING SECTORS
}

\author{
Peter Shaw ${ }^{1, *}$ and Ian Williams ${ }^{2}$ \\ ${ }^{1}$ Centre for Environmental Science, University of Southampton, United Kingdom \\ 2 Faculty of Engineering and Physical Science, University of Southampton, United Kingdom
}

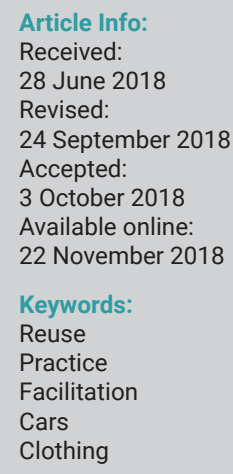

\begin{abstract}
Ongoing efforts to seek better resource efficiency have highlighted the role of reuse as a contributor to achieving circular economy objectives. In order to improve resource efficiency, the motives, means and opportunities for reuse need to be understood such that best practice can be identified and measures implemented to foster more effective and more extensive reuse. This study compares and contrasts reuse in the car and car components sector with the clothing sector as a means to identify commonalities and differences, and seek facets of effective practice. The car sector is found to align more with financial motives than the clothing sector, the latter providing more marked and apparent social benefits. Three key aspects appear common to both sectors. First, whole lifecycle - cradle to cradle - approaches to enhancing reuse are emerging and have considerable merit from a circular economy perspective. Secondly, the internet has become a key tool for the facilitation of reuse and is likely to grow further in this regard. Thirdly, decisions regarding the end-of-use of consumer products are critical and need to be better understood. Fourthly, for any reuse initiative to deliver positive outcomes, consumers must be fully engaged. We conclude that whilst some sector-specific adjustments may have to be implemented in future initiatives to promote and enhance reuse activities, the overarching principles and optimum methods of reuse facilitation may well be common for contrasting sectors.
\end{abstract}

\section{INTRODUCTION}

\subsection{Background and context}

It has been widely recognized that an urgent need exists for humankind to identify and apply means to achieve more effective, efficient and sustainable use of global resources. Approaches to resource use that recognize and respond to the call for due consideration of the environmental, social and economic facets of the production, provision and consumption of goods and services are widely supported. Indeed, the United Nations has called for "responsible production and consumption" at a global scale as their 12th Sustainable Development Goal (UN, 2015). The more efficient utilization of resources will likely be guided by key concepts, notably the waste hierarchy (EC, 2008; Williams, 2015) and the circular economy (Ellen MacArthur Foundation, 2017; EC, 2018), both of which highlight the role of reuse as a contributor to greater sustainability and advocate enhancement of reuse activities. In the case of the waste hierarchy, reuse is generally considered of lower preference than to "reduce" waste, but preferred to "recycle", "recover" or "dispose" (EC, 2008; Williams, 2015). In terms of circular economy concepts (Ellen MacArthur Foundation, 2017; EC, 2018; WRAP, 2018a), reuse offers a means to exploit more fully the utility of a product by extending its use beyond the point at which its owner considers it to have ceased providing them with the desired or needed function.

The aims and principles of reuse are well established (Williams and Shaw, 2017 and 2018). However, the practices of reuse in terms of what takes place, how it is achieved and what it achieves have been the subject of relatively little research (Cooper and Gutowski, 2017). In contrast, there has been considerable focus on recycling within the waste and resource management sector, allied with and driven by targets for recycling that are enshrined in policy and legislative frameworks on an extensive basis (e.g. EC, 2008). Likewise, targets for reduction of waste disposal to landfill are also enshrined in policy and law (e.g. EC, 1999 and 2008) and recycling is broadly recognized as a key factor in achieving reductions the quantities of waste that are landfilled (e.g. Farmer et al., 2015; UK Government, 2003).

It can be argued that ambitions to increase recycling and reduce disposal to landfill share a common feature. Provided that suitable infrastructure and recording methods are in place, quantities of recycled and landfilled materials are readily measurable. We suggest that, in addition to the overarching ambitions of targets for recycling enhance- 
ment and landfill reduction, the opportunity for measuring quantities of recycled and landfilled materials renders such targets attractive for reasons of practicality. The preponderance of targets and initiatives orientated towards recycling enhancement (e.g. EC, 2008; UK Government, 2003) and landfill reduction (e.g. EC, 1999) are driven, of course, by a rational and well-founded ambition to achieve environmentally-desirable outcomes; the facility or opportunity to measure performance in relation to the specified targets is, arguably, a further motivation for their adoption. Reuse, in contrast, appears less readily measurable and is, we contend, consequently a less common feature of waste management or resource efficiency targets. The existence of extensive and common informal networks (Williams and Shaw, 2017 and 2018), for example, offers a wide range and high number of opportunities for reuse that are not routinely accompanied by formal or extensive recording mechanisms.

\subsection{Aims of the study}

Notwithstanding the inherent challenges in setting meaningful targets for reuse and measuring performance in this regard, it remains that reuse comprises an integral and critical contributor to actions orientated towards resource efficiency and associated benefits. In order for reuse to occur, however, there are key prerequisites. First, there must be a desire on the part of individuals to participate in reuse, either as the current owner or the future owner of an item. Unless this desire exists for both current and future owners, reuse will likely not take place. Secondly, there must be means by which reuse might occur, i.e. a mechanism or facility that enables what is no longer needed or wanted by one party to be made known and available to another, and with a method for payment, if needed, to be made. In the light of these prerequisites, this study seeks to explore, through exemplification, current practice in reuse with specific focus on:

- Motives: drivers and benefits of reuse;

- Means: structures and methods to facilitate reuse.

On the basis of this review, an appraisal will be made of opportunities to enhance reuse, and recommendations made for future research.

\section{METHODS}

\subsection{Key definitions and terms}

On a formal basis, reuse is considered to include both products and components thereof, and also operations or processes that might be conducted before reuse takes place (Table 1). Although this illustrative example is specific to the European Community (EC, 2008), inclusion of these terms highlights important aspects of reuse in that items that are viable for reuse are restricted neither to whole items and products, nor to items or products that are reusable in the condition or state at which the present owner decides that they are no longer needed or wanted. These definitions (Table 1) highlight a key difference between reuse and preparing for reuse. It is inferred (Table 1) that reuse applies to items that have not become waste as such, whilst preparing for reuse relates to items that have indeed become waste prior to preparing for reuse.

\subsection{Case studies}

In view of the stated realm of reuse (Table 1) and the aims of the study (Section 1.2), a review of studies and information in the public domain was undertaken, with the intention of exploring and exemplifying current reuse practice. Selection of the sectors on which the study would focus was made with reference to four requirements. First, there should be potential for reuse of goods purchased when no longer needed or wanted. Secondly, a sector was required that was notable in terms of consumer spending activity; consumer spending on such goods should comprise a substantial part of general household spending. Thirdly, we sought to elucidate how sectors differ in terms of reuse as a function of the frequency of opportunities for reuse and the potential economic value associated with reuse. This aspect was a particular focus for the study as the drivers and benefits of reuse could be expected to differ according to the value of reused items, and with more costly and more durable items generally being retained for longer by the purchaser. Fourthly, items reused within the sectors selected should offer opportunities for reuse and preparing for reuse (Table 1). UK householders' spending revealed that many key purposes of spending were for goods and services that did not offer opportunities for reuse (Figure 1), comprising, for example, items intended for immediate consumption and access to services. Of the four spending purposes identified as having potential for the goods purchased to be reused, transport (including purchase of cars; Figure 1) is clearly a major area of household expenditure. Car purchases may be considered high cost and low turnover as a generalisation, and with opportunities for both reuse and preparing for reuse (Table 1). Of the other areas of household expenditure with clear potential for recycling, purchase of clothing is characterised, in general, with relatively modest costs and high turnover, and with potential for both reuse and preparing for reuse (Paras et al., 2018; Table 1). Although other areas of

TABLE 1: Definitions of key terms appertaining to waste and reuse, as set out in the EC Waste Framework Directive 2008/98/EC (EC, 2008).

\begin{tabular}{|c|c|}
\hline Term & Definition \\
\hline Waste & "...any substance or object which the holder discards or intends or is required to discard". \\
\hline Reuse & $\begin{array}{l}\text { "...any operation by which products or components that are not waste are used again for the same purpose for } \\
\text { which they were conceived." }\end{array}$ \\
\hline Preparing for reuse & $\begin{array}{l}\text { "...checking, cleaning or repairing recovery operations, by which products or components of products that have } \\
\text { become waste are prepared so that they can be re-used without any other pre-processing." }\end{array}$ \\
\hline
\end{tabular}


household expenditure also include reusable items (e.g. "durable" households goods such as cookers, washing machines; ONS, 2018), the cost and turnover of such items are, in general, higher and less rapid than items of clothing.

A comparison of the car and clothing sectors was made, these two contrasting sectors meeting requirements as stated. The UK serves as an illustrative exemplar in this instance due to the availability of data for both sectors, and the opportunity for reuse of clothing through charity shops (Diop and Shaw, 2018; Osterley and Williams, 2018). The reach of some businesses brings some international facets to this review by virtue of cross-border initiatives and activities. The intention in this instance is to compare and contrast current practice rather than to present a comprehensive review or to scrutinize and report upon discrete reuse initiatives or case studies (e.g. Beasley and Georgeson, 2016; WRAP, 2011), providing a means to illustrate the extant motives and means for reuse, and thereby explore opportunities for enhancement of reuse in broader terms (§1.2). The sectors selected for focus are outlined in Table 2. The two sectors selected are both major contributors to consumer-orientated economic activity in the UK (Figure 1; Table 2), and both are substantial in terms of the volume of sales and consumption of primary resources. There is a contrast in that clothing consumption is characterised by high volume sales of relatively inexpensive items, whilst the car industry is characterised by quantitatively lower sales volumes but contributes substantially in economic terms due to the much higher purchase costs of individual units. In addition, these two sectors contrast in terms of the opportunities for reuse of components and preparing whole products or components for reuse (Table 1).

\section{RESULTS}

\subsection{The automotive sector: cars and components}

\subsubsection{Overview}

Global production of cars (Table 2) was in the region of 74.5 million in 2017 (Statistica, 2018a) and contributes at major scale to global economic activity. In general, the financial cost of cars is sufficiently high that owners (private individuals, organizations or traders) seek financial gain by selling or trading vehicles when they are no longer needed or wanted. In the case of traders, there is a clear profit motive to hand. For others, the money generated via reuse (i.e. sale or trade-in) is commonly less than was initially paid for the vehicle and presents an opportunity to recoup a part of the initial cost rather than to make a profit. There is a well-established market in "used" cars, driven by demand from, for example, private buyers who cannot afford or do not wish to pay for a new vehicle, and trade buyers who seek to profit through buying and selling used vehicles. For 2014, it has been estimated that sales of used (reused) cars in the UK amounted to a market value of $£ 4.3$ billion (Statistica, 2018a).

The importance and influence of legislation and associated requirements with respect to vehicle reuse and recycling have been highlighted (e.g. Bellemann and Khare, 1999; Wahab et al., 2008; Go et al., 2008). Motivated by the potential gains in energy and material productivity through increased reuse and recycling (McKenna et al., 2013), statutory requirements pose challenges to the automative sector; statutory demands and the demands of customers both have to be met (McKenna et al., 2013). Resistance to reuse of components in new vehicles has been observed,

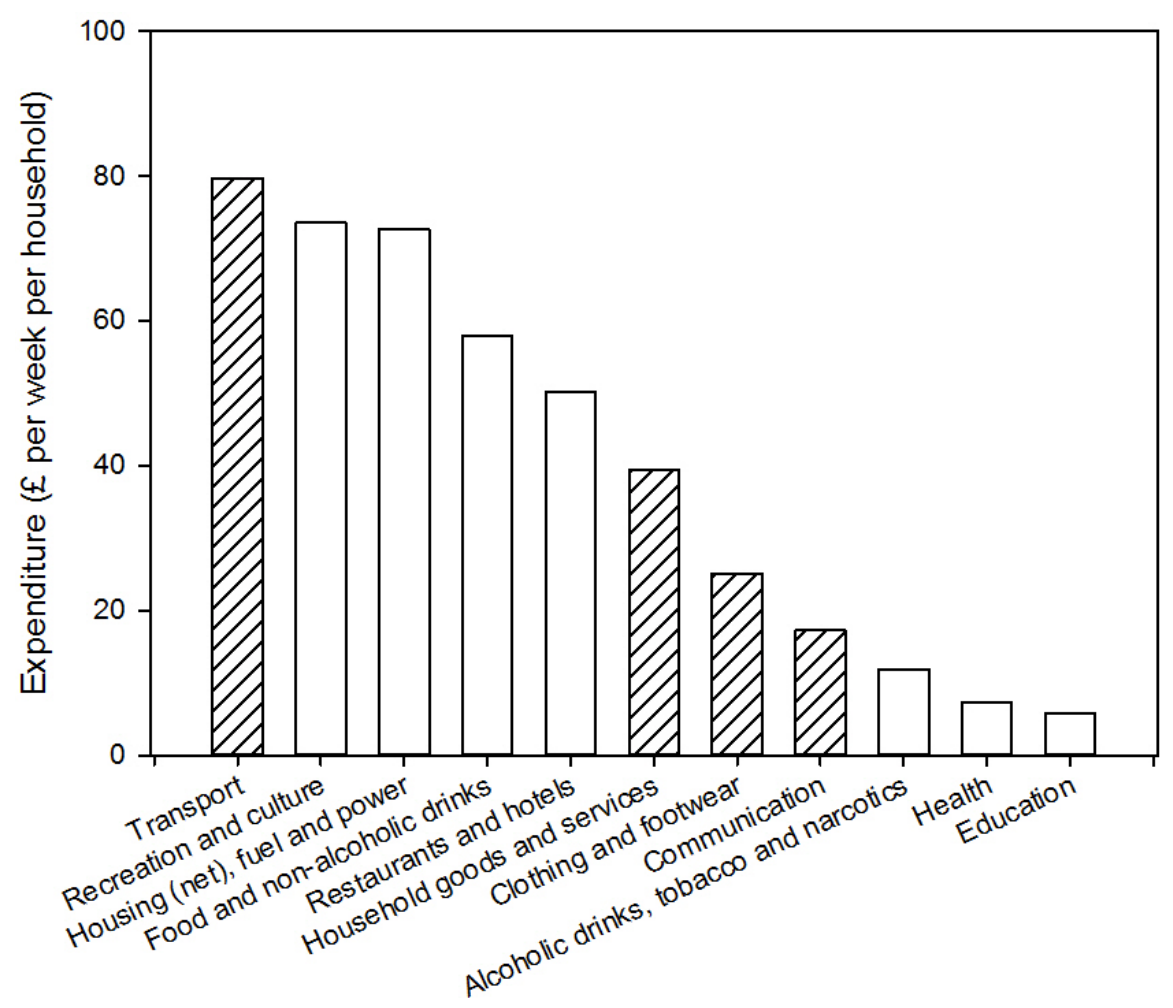

FIGURE 1: UK household expenditure in 2017. Data from ONS (2018). Shaded bars indicate sectors with opportunities for reuse. 
TABLE 2: Profiles of the automotive and clothing industries in the UK.

\begin{tabular}{ll} 
Sector & Notes \\
\hline In 2017 an estimated 74.5 million cars were produced globally (Statistica, 2018a). Reuse of automobiles (sec- \\
ond-hand/used) and components ("spares") is common and extensive. In 2016-2017, 79\% of UK households owned a \\
car or van (ONS, 2018). In 2017, 2,540,617 new vehicles were registered (SMMT, 2018c) and 8,113,020 (re)used cars \\
changed hands (SMMT, 2018d) . In 2015, the total weight of end-of-life vehicles in the UK was an estimated 966,657 \\
tonnes (Europa, 2018). \\
$\begin{array}{l}\text { The global clothing industry accounted for an estimated } \$ 2.4 \text { trillion in 2016 (Mackinsey and Co., 2017). Items of } \\
\text { clothing may be deemed "end-of-use" for reasons other than loss of utility; options for reuse are numerous and offer } \\
\text { opportunities for altruism (Diop and Shaw, 2018) and financial gain (Morley et al., 2009). Expenditure on clothing and } \\
\text { shoes in the UK was estimated at } £ 57.8 \text { billion in } 2017 \text { (Statistica, 2018b); every year in the UK clothing worth an esti- } \\
\text { mated an } £ 140 \text { million worth (ca. 350,000 tonnes) of used clothing is destined for landfill (WRAP, 2011). }\end{array}$ \\
Clothing
\end{tabular}

although opportunities for after-market reuse of components may arise (Amelia et al., 2009). Specific challenges for component reuse have been identified for tyres (Lebreton and Tuma, 2006) and plastics (Bellemann and Khare, 1999), for example. With regard to the necessary processes and facilities for direct secondary reuse of vehicle components (McKenna et al., 2013), the importance of approach(es) to disassembly appears critical. Identifying the optimal stage for disassembly is clearly important if the components recovered are to be of suitable economic value (Go et al., 2011), whilst designing components from a whole life-cycle perspective - including disassembly and reuse - is clearly a desirable step towards greater environmental sustainability in automotive manufacture (Wahab et al., 2008; Go et al., 2012;). With regard to disassembly, the question of "who does what?" is a further consideration and complication. As noted by Matsumoto (2009), options for reuse and remanufacture include both original motor manufacturers and independent reuse business companies.

\subsubsection{Reuse in practice: cars}

Selling and trading cars that have been previously owned by another party constitutes reuse (Table 1) and the means available to do so are numerous. Opportunities exist for exchanges between private individuals, between traders, and between private individuals and traders. Reused cars for sale may be advertised through online social media, web-based trading facilities, printed copy in local newspapers and magazines (specialist or general), whilst auctions, dealerships and associated marketing also offer information. Just over half of used car sales in the UK in 2014 were accounted for by sales from dealers (Statistica, 2018a).

Reuse of cars is clearly widespread and commonplace, if not routinely or widely considered as constituting "reuse" per se. In 2017, just over 2.5 million new cars were registered (SMMT, 2018a); over this same year, 8.1 million used (i.e. reused) cars changed ownership (SMMT, 2018b). Purchases of reused cars thus outnumber new car purchases at a ratio of ca. 3.25:1. When considered over a longer period, available data again illustrate the contribution of reused cars to the whole UK-wide stock of registered cars. By the end of 2016, some 7.8 million cars registered in the UK (24.5\% of the total) were recorded as having had a single "keeper" (Figure 2). The remaining $75.5 \%$ of all registered cars had been previously registered to another keeper, implying that $3 / 4$ of UK-registered cars at the end of 2016 were reused vehicles (Figure 2). Around 3 out of 10 UK-registered cars at this time had had one former keeper (reused once since first purchase) and 2 out of 10 had had two former keepers (reused twice since first purchase). In extreme cases, usually for cars first registered before 1979 , records show that some cars have been registered by 20 or more keepers, inferring that, albeit rarely, some cars had

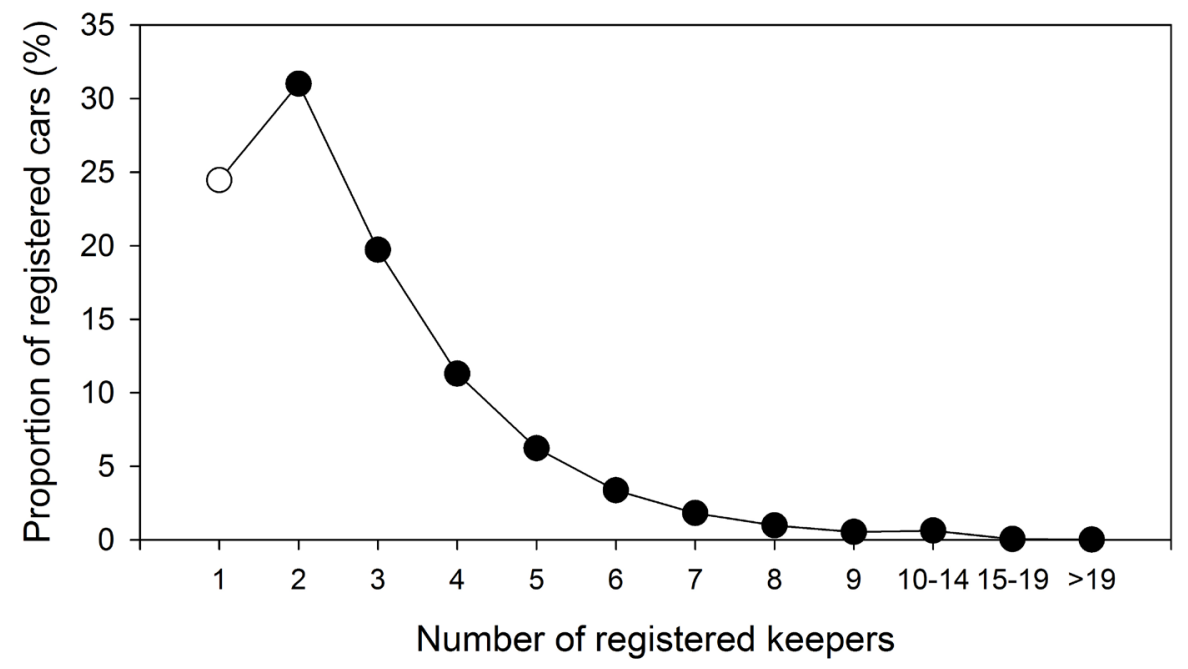

FIGURE 2: The proportions of UK-registered cars and corresponding number of keepers as recorded for 2016. The registered keeper is not necessarily the owner of the car; change of keeper usually signifies change of ownership. Open symbol represents new cars, closed symbols represent reused. Data from DfT (2017). 
changed hands 19 times or more.

We note that measures are in place in the UK (and elsewhere) regarding the fitness-for-purpose of reused cars in terms of tests for their roadworthiness. UK MOT (Ministry of Transport) certification is provided for vehicles that meet the minimum standards as set (UK Government, 2018) which broadly concern (1) legalities regarding identification and registration of vehicles, and (2) checks and inspections to ensure that the vehicle is of a roadworthy condition. The MOT system also makes available some facets of a vehicle's history (e.g. MOT history, recorded mileage) to a potential purchaser but does not cover some major mechanical systems: engine, clutch and gearbox are excluded. Further assurance that a reused car is sound with respect to these mechanical systems may be gleaned by independent inspection, but usually at additional cost for the services of automotive industry organizations or other industry professionals. MOT certification does not provide any guarantee to a prospective purchaser or a valuation of the vehicle. Warranties are commonly provided by registered traders, purchases from whom are covered by consumer law (UK Government, 2015). Private sales of vehicles are not regulated under the same framework; it is common practice that such sales are made "without warranty or guarantee", the onus being on the purchaser to ascertain the status of the vehicle over and above the MOT certification. It should also be noted that the preponderance of reused cars (Figure 2) generates a need for replacement components and parts. Failure, breakage or damage inevitably become more likely as the age and use of a vehicle increase, leading to a demand from owners which may be met in part by reused components and parts.

There are multiple means by which used cars are exchanged. Historically, vehicles no longer wanted or needed by the present owner have been advertised to prospective buyers via hard copy publications. Well known publications in the UK are "Exchange and Mart" and "Autotrader" both of which have adopted and adapted to internet-based formats in the light of widespread access to and use of web-based technologies and devices. From a potential buyer's perspective, there exist similarities in hard copy and digital formats: details of the vehicles for sale are provided in concise form, including make, model, age, colour, recorded mileage, presence or absence of MOT certificate, and usually a seller-provided description of the vehicle's condition. Public access to digital databases, however, offers great choice to the potential buyer and access to highly specific search tools. In addition to the details provided in hard copy format, it is usual to provide several photographic images of the vehicle to assist the potential buyer. With regard to the search for a vehicle, potential buyers may readily filter their search according to their preferences and desires. In addition to make, model, age, colour, recorded mileage, presence or absence of MOT certificate, on-line search engines (e.g. www.autotrader.co.uk, www.ebay. com/motors/carsandtrucks; www.gumtree.com/cars) can include numerous additional filters. Distance from the searcher's address, minimum and maximum price, body type, engine size, $\mathrm{CO}_{2}$ emissions, number of seats, gearbox and fuel consumption, plus other variables, can be speci- fied. Access to such tools is clearly advantageous in terms of vehicle reuse, in making more streamlined and controllable the ways in which sellers and buyers may be linked. We note that in terms of cost, the wide range and number of vehicles that can be viewed has impacts on both sellers and potential buyers. The price of a vehicle as advertised is readily comparable with prices of similar vehicles; the quasi "market value" of a vehicle as observed will thus likely influence the expected price from both sellers' and purchasers' perspectives.

\subsubsection{Reuse in practice: car components and parts}

Whilst formal targets for the reuse of whole vehicles appear absent in the UK, there are policies intended to ensure that reuse is embedded in the fate of end-of-life vehicles (ELV). The European Community ELV Directive (EC, 2000) for example, challenged manufacturers "to factor in the dismantling, reuse and recovery of the vehicles when designing and producing their products." Two targets were set within the ELV Directive (EC, 2000) for new vehicles in terms of (1) the percentage by weight per vehicle that should be reusable and/or recyclable (85\%), and (2) the percentage by weight per vehicle that should be reusable and/or recoverable (95\%).

Innovations within the car manufacturing industry have included "easy to dismantle" vehicles, through which manufacturers claim to have made less onerous the process of dismantling a vehicle such that most of the value of components and materials is not lost. The Toyota Motor Manufacturing Company, for example, promote "the four Rs" (Reduce, Reuse, Recycle, Recover) and have implemented a range of associated initiatives. With specific regard to reuse of vehicle parts and materials, key areas of activity are highlighted (Table 3). In this instance, remanufacturing of parts constitutes "preparing for reuse" according to EC definitions (Table 1). The stated reuse of hybrid and traction batteries (Table 3), however, does not lead to reuse in the same way as the components were used in the vehicle as initially produced. In this instance, "reuse" does not therefore formally accord with the definition as stated in the EC Waste Framework Directive (Table 1; EC, 2008).

In practice, the requirements of the EU ELV Directive (EC, 2000) and industry reuse innovations (e.g. Table 3) represent a re-casting of well-established and long-practiced activities. In particular, the reuse of vehicle parts has long existed in the form of "scrap yards", "breakers' yards" or "auto dismantlers", i.e. businesses providing a source of replacement car parts from ELVs. Such businesses commonly operate in differing modes. A "self-service" approach operates by customers being able to access ELVs stored in open-air yards and remove desired parts from vehicles themselves. Other businesses dismantle vehicles and salvage reusable and saleable parts, creating a stock of offthe-shelf parts and components; some will remove parts from ELVs to order. Inspection and reconditioning of parts (cf. Table 3) may be necessary for some components obtained from dismantlers or scrap yards. Components of a cosmetic nature (e.g. decorative body trim) may require only visual inspection as a means to ascertain their condition, whilst the condition of mechanical or electrical parts 
TABLE 3: Reuse initiatives promoted by the Toyota Motor Manufacturing Company (Toyota, 2018).

\begin{tabular}{|c|c|}
\hline Initiative & Notes \\
\hline Remanufacturing parts & $\begin{array}{l}\text { Remanufacturing programme for the European retailer network. Returned parts are inspected and reconditioned; } \\
\text { worn elements are replaced, and the part reassembled and packaged for sale to customers. Major items reman- } \\
\text { ufactured include air conditioning compressors, automatic transmissions, power steering racks, cylinder heads, } \\
\text { engines and clutch kits. }\end{array}$ \\
\hline Reusing hybrid batteries & $\begin{array}{l}\text { Nickel and lithium-based batteries used in hybrids may outlast the vehicles they power. Ongoing investigation } \\
\text { into how these might be remanufactured for repeat use in vehicles and/or be reused for other purposes; use for } \\
\text { stationary or emergency power storage units is being considered. }\end{array}$ \\
\hline Stationary storage; traction batteries & $\begin{array}{l}\text { Traction batteries for end-of-life hybrid vehicles, if in good working order, can be removed and used as a stand- } \\
\text { alone, stationary power storage unit. Applications may include co-ordinated energy-saving systems, or emer- } \\
\text { gency back-up supply. }\end{array}$ \\
\hline
\end{tabular}

may not be so readily assessed.

Issues of supply and demand present challenges in, and possible barriers to, reuse of ELV parts and components. In principle, a car owner seeking a specific replacement part for their own vehicle needs to locate a like-for-like part from an ELV "donor" vehicle that is suitably compatible (e.g. with respect to model, variant, age and potentially colour). Matching of parts may be easier in some instances than others. Where engines are used commonly for several different models of car from a single manufacturer, for example, components will more likely be engine-specific than model-specific. In contrast, other parts (e.g. body trim, interiors, lighting and body panels) will necessitate location of a more precise match of donor ELV.

The task of locating suitable parts for specific models has been made easier by the advent of searchable online databases of available parts and vehicles. Access to digital databases via the internet offers widespread access to vehicle dismantlers across broad geographic areas; webbased search tools provide access to national networks of auto dismantlers. Common practice in the past in the UK has been to locate a suitable donor vehicle was, by custom and practice, achieved by telephone conversations with yard operators, a practice rather limited by proximity of an individual to dismantling yards as well as the ELVs held in stock. Locating specific used parts to replace damaged or non-functioning car components requires, of course, a specific match. To this end, internet-based searching permits the customer to specify the necessary details and thereby locate a suitable part. There appear to be two modes by which such searches can be made. First, some dismantlers provide searchable lists of vehicles currently held in stock; in some instances the vehicles are routinely dismantled and parts held in stock; in other cases the details of vehicles are held to enable "self-service" to parts by customers. Networks of dismantlers offer a perhaps more effective approach enabling access to vehicle and parts held in stock by a large number of dismantlers. Such networks operate on an "enquiry" basis whereby the customer specifies the part(s) required. The enquiry is then circulated to network members, who respond to the query when a suitable part is available. The emails received by the enquirer then provide details of choice, availability, and cost. When the facility is available, entering the registration number for a vehicle permits the make, model and year to be readily identified and partner/network organizations may then be invited to respond via email to specific enquiries. This facil- ity enhances opportunities to locate suitable parts by opening up access to a high number of dismantlers distributed over a wider geographical (National) area and, at the same time, for purchasers to compare prices.

\subsection{The clothing sector}

\subsubsection{Overview}

The retail textile industry is a major contributor to economic activity (Table 2). Estimates of the economic scale of the global clothing market range from \$1.2 trillion in 2014 (Resta and Dotti, 2015) to \$2.4 trillion in 2016 (MacKinsey and Co., 2017). In the UK, consumers spend in the region of $£ 53$ billion per year on around 1.1 million tonnes of clothing, accounting for $5 \%$ of household expenditure (data for 2014: WRAP, 2016). Volumes of textiles destined for landfill at their end-of-use have in the past exceeded a million tonnes per year (WRAP, 2013). Consumer demand for clothing products (largely orientated to fashion) is increasing (Pookulangara and Shepard, 2013) and is likely associated with increases in textile waste arisings (Birtwistle and Moore, 2007).

Clear benefits of using recovered (recycled) materials rather than virgin resources have been demonstrated (e.g. Woolridge et al., 2006; Dhalbo et al., 2017; Esteve-Turillas et al., 2017); the benefits of clothing reuse have likewise been demonstrated and are likely to exceed the benefits of textile recycling (Sandin and Peters, 2018). At the same time, complexities in understanding the reuse of clothing have been identified. Consumers' behaviours are complex, involving, for example, compulsive purchases and value-orientated hoarding (Joung, 2013). Behaviours relating to clothing and its reuse may also be orientated to the consumers' level of materialism (Joung, 2013) and their status as "fashion consumers" or "non-fashion consumers" (Weber et al., 2017). Factors influencing reuse may also be many and varied, including environmental concerns, economic concerns, concerns for charity, subjective norms (Joung and Park-Poaps, 2013), convenience (Laitala, 2014); and a personal preference for antique items, clothing from a past era and/or a particular "look" (e.g. steampunk, gothic, rock'n' roll, military, anime, etc).

\subsubsection{Reuse in practice: clothing}

The fate of end-of-use clothing is clearly of concern in terms of environmental impacts and sustainability, and yet determination of consumers' post-purchase behaviour with regard to clothing has in the past received relatively 
little attention in the research literature (Joung, 2013). If items of clothing that retain utility are destined for landfill or incineration, for example, the value of the resources used in their production (e.g. raw materials and energy) and delivery to the point of sale (e.g. packaging and transport) will not be fully realised.

Whilst there are uncertainties regarding the destinations and ultimate fates of end-of-use clothing with regard to their reuse or recycling, prior research has given some indication of the relative quantities in this regard (Figure 3). Substantial quantities of clothing are evidently exported from the UK for reuse or recycling. In 2007, for example, 368,000 tonnes of clothing were exported from the UK (Morley et al., 2009). Quantities of textiles intended for reuse within the UK are considerably higher than for recycling or export (Figure 3). Indeed, the ratio of reuse to recycling on a weight basis (Figure 3 ) is $4.6: 1$ for the UK and 6.1:1 for exported textiles. Uncertainties regarding the fate of exported items have been previously reported (Morley et al. 2009); exports are deemed beyond the scope of this study.

There are economic benefits in ensuring that clothing items are reused and their premature disposal is avoided. Estimates suggest that over 350,000 tonnes of potentially reusable textiles are disposed of or recycled per year; reuse of textiles in England could save the tax payer $£ 35$ million per year via avoided disposal costs, and the resale value of reusable items could be over $£ 140$ million (LGA, 2014). Recycling and reuse of clothing have differing merits. Whilst avoidance of disposal has benefits in economic and environmental terms, the motivation for promotion and enhancement of reuse of clothing is additionally orientated to social benefits (LGA, 2014). Funds may be raised for charitable purposes through the sale of reused items (Osterley and Williams, 2018) and, at the same time, low-cost clothing is made available to those with limited income (Diop and Shaw, 2018) or who wish to purchase reused items as a lifestyle choice (Williams and Shaw, 2017).
Opportunities for reuse of clothing in the UK mainly occur in two modes: donations or sales. The means for reuse thus contrast, although some (e.g. internet-based means) permit access on a broad geographical scale. It is noted that in all cases the expense of purchasing new items and the need for production of new products are reduced or avoided (Table 4).

\section{Donation to a personal acquaintance}

Donation and exchange of clothing items between friends, neighbours, family and other acquaintances are, for obvious reasons, not formally recorded. Estimates have been made, however: together with items sold or exchanged on-line, direct reuse of clothing in this form may account for around 100,000 tonnes per year (WRAP, 2016). Such figures are encouraging, but there are no doubt more opportunities in this regard: reusable items may be placed by householders into kerbside-collected refuse bins rather than given to others living in close proximity or with whom householders are in regular contact. Local authorities have noted the placement of reusable items in kerbside-collected refuse bins, including clothing, and taken steps to encourage householders to reuse rather than dispose of suitable items (e.g. SCC, 2018). Anecdotally, donation and exchange of clothing items appear well-developed amongst families with young children. In this context, two observations may be made: (1) clothing items are often outgrown by children before they become excessively worn and their utility is diminished, and (2) social networks and contacts to facilitate reuse are readily available in the form of social media and informal encounters through school-related activities. We note that donations in this manner comprise "giving" of clothing items as opposed to "gifting" via donations to a charity or similar organization (Diop and Shaw, 2018).

\section{Donation through a reuse group or event}

As with direct donations to known individuals, donation

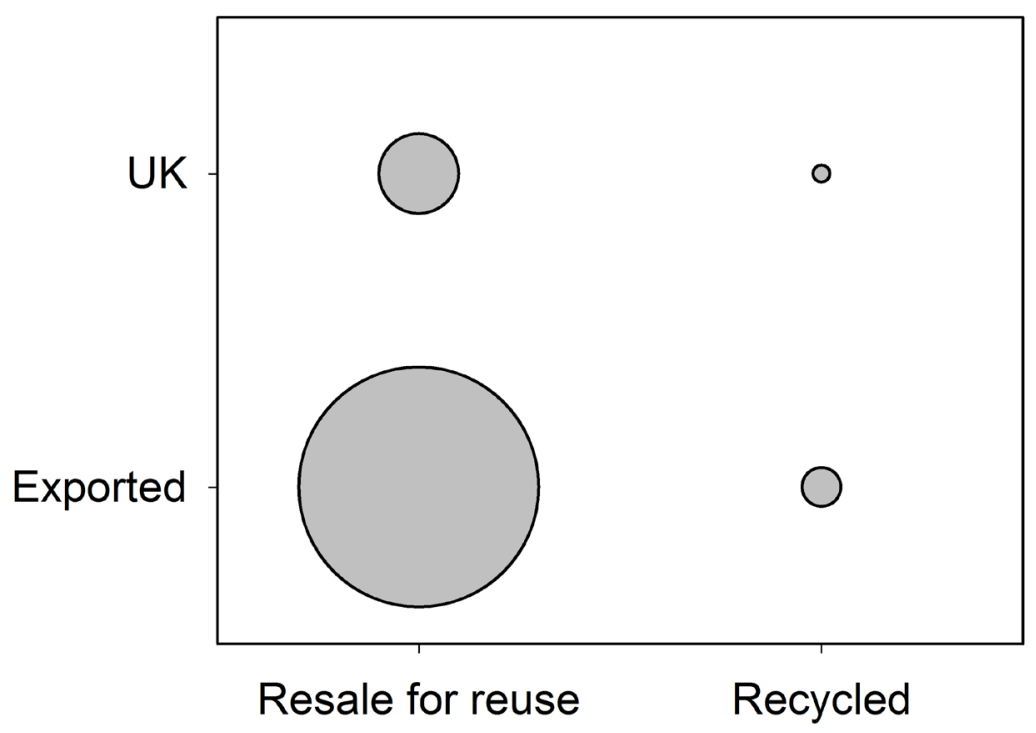

FIGURE 3: The relative quantities (by weight) of textiles sent for reuse or recycling in the UK in 2007. Data from Morley et al. (2009). Areas of symbols are proportional to total weight for 2007. 
TABLE 4: Examples of main clothing reuse opportunities for consumers and their associated benefits

\begin{tabular}{|c|c|c|}
\hline Initiative & Recipient & Benefit(s) - examples \\
\hline Donate to a personal acquaintance. & Friend, neighbour, family, colleague etc. & $\begin{array}{l}\text { Avoided expense of purchasing new items; avoided need for production } \\
\text { of new items "feel-good" factor for donor; reinforcement of social rela- } \\
\text { tionships. }\end{array}$ \\
\hline $\begin{array}{l}\text { Donate to an unknown person } \\
\text { through reuse group. }\end{array}$ & Reuse group member & $\begin{array}{l}\text { Avoided expense of purchasing new items; avoided need for production } \\
\text { of new items. }\end{array}$ \\
\hline $\begin{array}{l}\text { Donate to a charity or third sector } \\
\text { organisation (TSO). }\end{array}$ & $\begin{array}{l}\text { Charities with UK and/or international } \\
\text { remit. }\end{array}$ & $\begin{array}{l}\text { Avoided expense of purchasing new items; avoided need for production } \\
\text { of new items "feel-good" factor for donor; provision of low cost items } \\
\text { through charity shops/outlets; employment. }\end{array}$ \\
\hline $\begin{array}{l}\text { Direct resale via websites, local } \\
\text { newspapers, car boot sales. }\end{array}$ & Purchaser & $\begin{array}{l}\text { Avoided expense of purchasing new items; avoided need for production } \\
\text { of new items; income for vendor. }\end{array}$ \\
\hline
\end{tabular}

and exchange of clothing items through the use of reuse groups and events remains largely unrecorded. Reuse activity within this domain has largely arisen and expanded by virtue of the internet and associated facilities. Web-orientated organizations can offer, in principle, facility for the exchange of clothing items; perusal of currently-available goods and products tends to reveal bias towards, for example, household items, garden equipment and toys. There are web-orientated initiatives becoming available that are focusing more specifically upon clothing (e.g. myfamilyclub.co.uk).

"Swap Shops" for clothing offer a perhaps more suitable forum for exchange of clothing items (WRAP, 2018d). These events involve individuals taking unwanted items of clothing to a venue (e.g. community centre) and select unwanted items that have been brought by others. It is usual practice that direct payments for items of clothing are not involved. Since these events usually involve physical access to items, fuller evaluation of quality, size and suitability for a potential new owner is permitted. So-called "Swishing Events" generally follow the same format and functions as Swap Shops, in cases with emphasis on accessories and shoes as well as clothing (WRAP, 2018d). These are now well-established in the UK and are wellserved by guidance and promotion (e.g. Love Your Clothes, 2018; WRAP, 2018b).

\section{Donation to a charity or third sector organization}

Donations of clothing to charities and third sector organizations (TSOs) are widely considered the main route for clothing reuse in the UK (WRAP, 2016). Such donations may be considered "gifting" (Diop and Shaw, 2018) since the items are gifted to an organization for resale. Donations to charity shops in the UK have been estimated to lead to around 310,000 tonnes of textiles per year being diverted from landfill (Osterley and Williams, 2018). Moreover, there are social and economic benefits. In the UK, activity in the charity/TSO sector is associated with the creation of employment (LGA, 2014); there are around 11,200 charity shops employing some 23,000 paid staff and 230,000 volunteers (Osterley and Williams, 2018). As noted (Table 4), the donor may well value the "feel-good" aspects of such donations through the expected benefit(s) for the receiving charity and those causes supported financially by the subsequent sale of donated items. At the same time, reused items are made available for purchase by those who seek reused clothing at low price, out of desire or necessity (Williams and Shaw, 2017). Both these outcomes are important social benefits of clothing reuse. As noted by the LGA (2014), the low price of secondhand items is in general the biggest motivator for their purchase. Donations to charities and TSOs are also actively promoted by third parties: local authority messages intended to dissuade householders from placing items of clothing in residual waste bins suggest reuse by using charity shops and textile banks, for example (SCC, 2018).

\section{Selling for personal financial gain}

Direct resale and reuse of personal possessions is far from new. So-called "small ads" (i.e. newspaper advertisements), notes on display in local shops and in specialist publications have for decades been commonly used to advertise a wide variety of possessions. When clothing has been advertised in this manner, focus has frequently been upon items of higher value (e.g. wedding attire, formal wear and men's suits) or "as new" (little worn or unworn), commonly with the intention of selling rather than giving away. Car boot sales have also offered opportunities for resale and reuse of clothing, amongst a wide range of household possessions (Gregson and Crewe, 1994). These events are commonly set according to a repeated schedule; goods are brought in cars or small vans and sold direct from the boot (trunk) of a car, or items are set out on display on folding tables or on tarpaulins on the ground (Williams and Shaw, 2018). There is usually a modest charge for vendors and occasionally a smaller charge for entry by the public.

Use of internet-based technologies is also recognized as a key means to enhance sale, donation or swapping of clothing (Morley et al., 2009). Sales of reused clothing have been particularly influenced by activities in this regard, notably through the launch of the "ebay" internet site in 1995. The advent and wide ownership of smart 'phones and internet-enabled handheld devices have no doubt amplified the role and impact of ebay and similar web-based entities by permitting highly flexible and mobile trading and exchange of reused clothing. The advent of other internet-based businesses has also offered individuals greater opportunities for resale of clothing: there is a plethora of such websites including preloved.co.uk, vinted.co.uk, and whowhatwear. com, for example. It is notable that in many instances the primary focus of such initiatives is personal financial gain, e.g. "6 ways to make money from your closet clear-out" 
(Foreveramber, 2017). A small number of companies have started to view the provision of clothing as a service via leasing rather than as a product offering (e.g. MUD Jeans, 2018).

\subsubsection{Clothing reuse in the broader context}

Enhancement of reuse opportunities for clothing focuses not only on the donation and sale of used items for reuse (Table 4) but also adopts a broader view of reuse in the more general context of production, use, resale and recycling. The UK-based Sustainable Clothing Action Plan (SCAP: WRAP, 2018c), for example, advocates “... using collective action to minimise the environmental impact of our clothes." This initiative (Table 5) sets a wide-ranging agenda that recognises the interdependencies and connections to hand. Decisions regarding resources used, clothing designs and materials are critical and can, in principle, be made such that the durability of clothing products is enhanced. If combined with suitable adjustments of consumers' behaviour by persuading people to "make the most of their wardrobe", for example (WRAP, 2018b), the overall impact associated with the production, use, reuse and final destination of end-of-use clothing can be much reduced.

Whilst initiatives such as SCAP (WRAP, 2018c) offer the prospect of more and better with regard to clothing reuse, there remain challenges. There is the prospect that urban mines (Ongondo et al., 2015) represent an under-exploited source of reusable clothing. Estimates suggest that around $30 \%$ of the clothes in UK wardrobes have not been worn by their owner for at least one year, and around $80 \%$ of individuals own clothes that no longer fit them or need altering in order to be worn (WRAP, 2018b). At the same time, extending the useful lifespan of clothing can be achieved by design and fabric/fibre selection (Table 5); repair can also contribute in this regard, constituting "preparing for reuse" (Table 1). It is arguable, if speculative, that repair skills in the 21 st Century are less widespread than hitherto, but there is at least some appetite for learning more about repairing clothes (WRAP, 2018b), albeit lower amongst men (25\%) than amongst women (>50\%). Skills with regard to the repair of clothing will likely contribute to extending the utility of items, but the role of repair in terms of reuse and its contributions to reuse activities remains largely unknown. Mending an article of clothing may, for example, extend its utility for the existing owner, which has obvious merit in terms of avoided expense of purchasing new items and avoided need for production of new items.
Alternatively, repair skills could be employed to mend or alter second-hand items bought at low cost, inferring that repair-orientated skills offer opportunities for cost-saving as long as there is a desire to purchase reused items and apply repair skills.

\section{DISCUSSION}

The clothing and car sectors clearly differ in terms of reuse practice in some respects. As a broad generalization, the reuse of cars and their components is orientated primarily to resale for financial gain or purchase at lower cost than the equivalent new product or component; some manufacturer-level initiatives (Toyota, 2018) align with motives of resource efficiency (Table 3). There are, however, known challenges regarding component (e.g. tyres; Lebreton and Tuma, 2006) and material (e.g. plastic; Bellemann and Khare, 1999) reuse and practice elsewhere indicates a lack of reuse (Ameilia et al., 2009). In contrast, reuse of clothing appears commonly orientated around acts of altruism, whether to organizations (charities or TSOs) or individuals (§3.2.2), although involvement of clothing-related businesses is clearly aligned with and complementary to existing reuse activities (WRAP, 2018a,c). It is likely that this difference in orientation reflects the relative financial value of clothes and cars; donating an item of clothing may well be financially viable for an individual whilst the value of a used (i.e. reused) car would be too high to be lost through its donation. The impact of this difference is that whilst donations of clothing contribute to the well-being of others (e.g. through income raised by charity shops and/or benefits of free or low cost clothing), the sale of cars or car components has a specific benefit in that reuse supports an extensive market in which cars and components are available at lower cost than the equivalent new products. The social value of car and components reuse is thus, arguably, lower than for clothing.

We note that some commonalities between car and clothing reuse are also apparent. Notably, lifecycle ("cradle to cradle"; Braungart and McDonough, 2009) approaches are evident. Within the car sector, the ambition to produce "easy to dismantle" vehicles (e.g. Toyota, 2018; Table 3) signifies the importance of design in enabling and enhancing the potential for reuse of components. Similarly, the Sustainable Clothing Action Plan (WRAP, 2018c) recognizes the role and importance of product design in improving durability of products as a means to support reuse (Table 5). In both these cases, ongoing initiatives accord well

TABLE 5: Initiatives promoted via the Sustainable Clothing Action Plan (SCAP: WRAP, 2018c).

\begin{tabular}{|c|c|}
\hline Initiative & Reuse context: notes \\
\hline Resource efficient business models & $\begin{array}{l}\text { Intended to help: create commercial value from sustainable business practices; develop new revenue streams } \\
\text { and products from resources previously considered waste. }\end{array}$ \\
\hline Design for extending clothing life & \multirow{2}{*}{$\begin{array}{l}\text { Improved durability of clothing to increase rates of reuse through extended life and increased desirability for } \\
\text { consumers. }\end{array}$} \\
\hline Fibre and fabric selection & \\
\hline $\begin{array}{l}\text { Consumer behaviour and sustainable } \\
\text { clothing }\end{array}$ & $\begin{array}{l}\text { Intended to provide practical tips to householders with respect to: reducing environmental impacts of clothing } \\
\text { laundry, dealing with unwanted clothes, and making the most of their wardrobe (WRAP, 2018b). }\end{array}$ \\
\hline Reuse and recycling & $\begin{array}{l}\text { Voluntary agreement intended to enable re-use organisations, reprocessors and local authorities to increase } \\
\text { collection rates through partnerships, schemes, and advice on good practice. }\end{array}$ \\
\hline
\end{tabular}


with the aims and principles of the circular economy (Ellen MacArthur Foundation, 2017; WRAP, 2018a).

A further commonality is also evident in that the internet provides a means for reuse to take place for clothing, cars and car components. Whether allied with donations (to acquaintances or persons unknown) or sales, internet-based initiatives offer access to products at a scale that arguably surpasses all foregoing means and opportunities. For accessing reused products for sale, internet-based technologies provide searchable and conveniently-accessed databases for prospective buyers. This facility is broadly and commonly available for the purchase of reused cars and car components (§3.1), and for the sale or donation of clothing (§3.2.2). Searchable internet-based databases permit access to a wide range of items for sale over a large geographic area, providing insight to the range, variety and costs of items being sought. From a purchaser's perspective, the ease of access is perhaps counteracted in part by the inability to inspect closely items of interest. For clothing, size, fit, condition and texture will not be readily assessed. For cars, potential purchasers will frequently arrange a viewing prior to deciding whether to purchase a vehicle; for parts or components located on internet databases, scrutiny is likely less common or practicable, depending on the proximity of the vendor and potential buyer. In both cases, the prospect of "buying blind" incurs risks for the purchaser. Given the ongoing reliance of human society on digital and mobile communications, we suggest that it is likely that internet will continue to facilitate reuse activities and grow in this regard.

The decisions regarding why and how end-of-use decisions are made merits consideration. Whilst the foregoing review identifies and evaluates examples of current practice, it must be borne in mind that reuse is of lower preference than "reduce" in relation to the objectives of the waste hierarchy (EC, 2008; Williams, 2015). An individual's decision that a possession is no longer wanted or needed is critical in this regard; arguably, the differentiation between "want" and "need" is subjective but critical. Moreover, continued use of products - in the case of both cars and clothing - is contingent on maintaining their utility. In this respect, repair may be of particular importance. The issue of economic viability of repairs to cars is critical, i.e. the cost of repair(s) relative to the value of the vehicle must be favourable. Availability of reused components offers a means to reduce the cost of replacement parts and thereby favourably alters the balance of repair costs in relation to vehicle value, provided that the vehicle owner has necessary and sufficient skills to carry out the repair or can locate a technically-competent mechanic willing to work with reused replacement parts. For clothing, carrying out repairs and alterations relies on skills and, if carried out by the owner, may incur little in terms of cost whilst requiring time.

Finally, we observe that there remain challenges to the enhancement and expansion of reuse in both the sectors considered in the present study and more broadly within the consumer goods sector. Reuse has, until relatively recently, developed on a progressively evolving basis, led by opportunities that serve the needs, aspirations and desires of the population. The advent of whole lifecycle thinking (includ- ing aspirations to progress to a circular economy) introduces a need for deeper and wider understanding. Paras et al. (2018) proposed six primary drivers that need to be recognized in the implementation of a reuse-based value chain: the system at hand, redesignability and price of products, information, legislation, and consumer attitude. For the car components sector there is an additional challenge in that systems for disassembly must be considered and appropriately designed (Wahab et al., 2008; Go et al., 2011).

If achievable, a shift to a value chain approach could, in principle, be of considerable merit, but we note that the reuse practices presented in this study all involve, in some shape or form, a necessity for consumers to align their motives and actions with the aims and facilities of systems for reuse. The advancement in technology may hinder progress, but in different ways for cars and clothing. There is potential for tension between increasing technological complexity (e.g. of cars and their mechanical systems) that may well render repair or replacement the domain of technical experts. For clothing, the durability of products may be reduced by both fashion considerations and by a shift to cheaper materials and lower production costs. It is difficult how to envisage how such changes might be accommodated within a "cradle-to-cradle" lifecycle design approach as set out in the SCAP (Table 5; WRAP, 2018c). Such changes and differences between product sectors need to be taken into account when designing systems for reuse (Tables 3 and 5); this comprises an area in which sector-specific aspects will need to be taken into account and fully recognised.

\section{CONCLUSIONS}

As noted by Williams and Shaw (2017), it is clear that reuse has a critical and central role in progressing towards more sustainable use of resources orientated to circular economy thinking; it is crucial that reuse continues to serve and contribute to our ambitions to achieve responsible production and consumption (UN, 2015). If we as a society are to achieve this ambition, sector-specific adjustments may have to be implemented in future initiatives to promote and enhance reuse activities. Overarching principles and optimum methods of reuse facilitation may well, however, be common for different sectors. In this regard, the shift towards full lifecycle product design, incorporating all stages from "cradle to cradle" (Braungart and McDonough, 2009; WRAP, 2018c) has, we believe, considerable merit as a means to enhance and expand reuse activity. Such approaches, however, are unlikely to succeed in their aims unless consumers are fully engaged in reuse. For their engagement to occur, the internet in particular provides opportunities for reuse, offering access to and choice of reused products that appears independent of sector in the case of cars and clothing and may indeed provide a tool for more and better reuse in other sectors.

\section{REFERENCES}

Amelia L., Wahab D.A., Che Haron C.H., Muhamad N. and Azhari C.H. (2009). Initiating automotive component reuse in Malaysia. J. Clean. Prod. vol. 17, 1572-1579. 
Beasley J. and Georgeson R. (2016). Reuse in the UK and Ireland a "State of the Nations" report for the Chartered Institution of Wastes Management. https://www.ciwm-journal.co.uk/downloads/Reuse-in-the-UK-and-Ireland-WEB.pdf [last accessed 12/3/2018]

Bellmann K. and Khare A. (1999). European response to issues in recycling car plastics. Technovation, vol.19, 721-734.

Birtwistle G. and Moore C. M. (2007). Fashion clothing - where does it all end up? Int. J. Retail Dist. Manage., vol. 35, 210-216.

Braungart M. and McDonough W. (2009). Cradle to cradle: remaking the way we make things. Vintage Paperbacks; London.

Department for Transport (DfT) (2017). Vehicle licensing statistics. https://www.gov.uk/government/collections/vehicles-statistics [last accessed 11/3/2018]

Dahlbo H., Aalto K., Eskelinen H. and Salmenperä H.(2017). Increasing textile circulation - consequences and requirements. Sust. Prod. Cons., vol. 9, 44-57.

Diop, S.-A. and Shaw, P.J. (2018). End of use textiles: gifting and giving in relation to societal and situational factors. Detritus, vol. $1155-$ 161.

Ellen MacArthur Foundation (2017). What is a circular economy? https://www.ellenmacarthurfoundation.org/circular-economy [last accessed 12/3/2018].

Esteve-Turrillas F.A. and de la Guardia M. (2017). Environmental impact of recover cotton in textile industry. Resourc. Cons. Recycl. vol. 116, 107-115.

European Community (EC) (1999) EC Landfill Directive 1999/31/ EC https://eur-lex.europa.eu/legal-content/en/TXT/?uri=CELEX\%3A31999L0031 [accessed 21/6/2018].

EC (2000). End-of-life Vehicles Directive 2000/53/EC (2000). http://eurlex.europa.eu/legal-content/EN/TXT/?uri=legissum:I21225 [last accessed 12/3/2018]

EC (2008). Waste Framework Directive 2008/98/EC (2008). http:// ec.europa.eu/environment/waste/framework/ [last accessed $12 / 3 / 2018]$.

EC (2018). Circular Economy: Implementation of the Circular Economy Action Plan, 2018 Circular Economy Package. http://ec.europa. eu/environment/circular-economy/index_en.htm [last accessed $21 / 6 / 2018]$.

Europa (2018). End-of-life vehicle statistics. https://ec.europa.eu/ eurostat/statistics-explained/index.php/End-of-life_vehicle_statistics\#Total_weight_of_end-of-life_vehicles [last accessed 19/9/2018].

Farmer T.D., Shaw P.J. and Williams, I.D. (2015). Destined for indecision? A critical analysis of waste management practices in England from 1996 to 2013. Waste Manage. vol. 39 266-276.

Foreveramber (2017). 6 ways to make money from your closet clearout. http://www.foreveramber.co.uk/where-to-sell-used-clothes [last accessed 12/3/2018]

Go T.F., Wahab D.A., Rahman M.N.A., Ramli R. and Azhari C.H. (2011) Disassemblability of end-of-life vehicle: a critical review of evaluation methods. J. Clean. Prod. vo. 19, 1536-1546.

Go T.F., Wahab D.A., Rahman M.N.A., Ramli and Hussain R.A. (2012) Genetically optimised disassembly sequence for automotive component reuse. Exp. Syst. Appl., vol. 39, 5409-5417.

Gregson N. and Crewe L. (1994). Beyond the high street and the mall: car boot fairs and the new geographies of consumption in the 1990s. Area vol. 26, 261-267.

Joung H-M (2013) Materialism and clothing post-purchase behaviors, J. Cons. Market., vol. 30, 530-537.

Joung H-M and Park-Poaps H. (2013). Factors motivating and influencing clothing disposal behaviours. Int. J. Cons. Stud, vol. 37, 105-111

Laitala K. (2014). Consumers' clothing disposal behaviour - a synthesis of research results. Int. J. Cons. Stud., vol. 38, 444-457.

Lebreton B. and Tuma A. (2006). A quantitative approach to assessing the profitability of car and truck tire remanufacturing. Int. J. Prod. Econ., vol 104, 639-652.

Local Government Association (LGA) (2014) Routes to reuse: maximising value from reused materials. Local Government Association; London.

Love Your Clothes (2018). How to organise a successful swishing clothes swap event. https://www.loveyourclothes.org.uk [last accessed 13/3/2018].
McKenna R., Reith S., Cail S., Kessler A. and Fichtner W. (2013). Energy savings through direct secondary reuse: an exemplary analysis of the German automotive sector. J. Clean. Prod. vol. 52, 103-112.

McKinsey and Company (2017) The state of fashion 2017. McKinsey and Company. https://www.mckinsey.com/industries/retail/ our-insights/the-state-of-fashion [last accessed 12/3/2018].

Matsumoto M. (2009). Business frameworks for sustainable society: a case study on reuse industries in Japan. J. Clean. Prod. vol. 17, 15471555.

Morley N.J., Bartlett, C. and McGill I. (2009). Maximising reuse and recycling of UK clothing and textiles: a report to the Department for Environment, Food and Rural Affairs. Oakdene Hollins Ltd.

MUD Jeans (2018) How lease jeans works. https://mudjeans.eu/howlease-a-jeans-works/) [Last accessed 21/9/2018].

Office for National Statistics (ONS) (2018) Percentage of households with durable goods, UK. https://www.ons.gov.uk/peoplepopulationandcommunity/personalandhouseholdfinances/expenditure/ datasets/percentageofhouseholdswithdurablegoodsuktablea45 [Last accessed 19/9/2018].

Ongondo F.O., Williams I.D. and Whitlock G. (2015). Distinct urban mines: exploiting secondary resources in unique anthropogenic spaces. Waste Manage. vol. 45, 4-9.

Osterley R. and Williams I.D. (2018). The benefits of reuse via charity shops. Proceedings of SUM2018, Fourth Symposium on Urban Mining, 21-23 May 2018, Bergamo, Italy.

Paras M.K., Pal R and Ekwall D. (2018) Systematic literature review to develop a conceptual framework for a reuse-based clothing value chain. Int. Rev. Retail, Dist. Cons. Res., vol. 28:3, 231-258,

Pookulangara S. and Shepard A. (2013). Slow fashion movement: understanding consumer perceptions - an exploratory study. J. Retail. Cons. Serv., vol. 20, 200-206.

Resta B. and Dotti S. (2015). Environmental impact assessment methods for textiles and clothing. In: Muthu S.S. (ed.), Handbook of life cycle assessment (LCA) of textiles and clothing, pp. 149-191. Elsevier; London.

Sandin G. and Peters G.M. (2017) Environmental impact of textile reuse and recycling e: a review. J. Clean. Prod., vol. 184, 353-365.

Society of Motor Manufacturers and Traders (SMMT) (2018a). Car registrations. https://www.smmt.co.uk/vehicle-data/car-registrations/ [last accessed 11/3/2018].

SMMT (2018b). Used car sales data. https://www.smmt.co.uk/ category/vehicle-data/used-car-sales-figures/ [last accessed $11 / 3 / 2018]$.

SMMT (2018c). UK new car market declines in 2017 but demand still third highest in 10 years. https://www.smmt.co.uk/2018/01/ uk-new-car-market-declines-2017-demand-still-third-highest-10years/ [last accessed 19/9/2018].

SMMT (2018d). https://www.smmt.co.uk/2018/02/uk-used-car-market-stays-strong-2017-8-1-million-vehicles-change-hands/ [last accessed 19/9/2018]

Southampton City Council (SCC) (2018). Clothing and textiles. https:// www.southampton.gov.uk/bins-recycling/recycling/reduce-reuse-recycle/clothing.aspx [last accessed 13/3/2018].

Statistica (2018a). Worldwide automobile production from 2000 to 2017. https://www.statista.com/statistics/262747/worldwide-automobile-production-since-2000/ [last accessed 26-6-2018].

Statistica (2018b). Apparel market in the United Kingdom (UK) - Statistics and Facts. https://www.statista.com/topics/3348/apparelmarket-in-the-uk/ [last accessed 19-9-2018].

Toyota Motor Manufacturing Company (2018). Better Earth. https:// www.toyota.co.uk/world-of-toyota/environment/better-earth.json [last accessed 11/3/2018].

UK Government (2003) Household Waste Recycling Act, 20003. http:// www.legislation.gov.uk/ukpga/2003/29/contents [last accessed 25-6-2018].

UK Government (2015) Consumer Rights Act 2015

http://www.legislation.gov.uk/ukpga/2015/15/pdfs/ukpga_20150015_en.pdf [21 accessed /6/2018].

UK Government (2018). Car parts checked at an MOT. https://www. gov.uk/government/publications/car-parts-checked-at-an-mot/ car-parts-checked-at-an-mot [last accessed 12/3/2018].

United Nations (UN) (2015). Sustainable development goals. http:// www.un.org/sustainabledevelopment/sustainable-development-goals/ [last accessed 11/3/2018]. 
Wahab D.A., Amelia L., Hooi N.K., Che Haron C.H. and Azhari C.H. (2008). The application of artificial intelligence in optimisation of automotive components for reuse. J. Achieve. Mater. Manufact. Eng., vol. 31 595-601.

Waste and Resources Action Programme (WRAP) (2011). Benefits of reuse case study: clothing. WRAP, Banbury.

WRAP (2011). Valuing our clothes: the true cost of how we design, use and dispose of our clothing in the UK. WRAP, Banbury.

WRAP (2013). UK textile product flow and market development opportunities. Oakdene Hollins, London. http://www.wrap.org.uk/content/uk-textile-product-flow-and-market-development-opportunities [last accessed 30th August 2016]

WRAP (2016). Textiles: market situation report. WRAP, Banbury.

WRAP (2018a). WRAP and the circular economy. http://www.wrap. org.uk/about-us/about/wrap-and-circular-economy [last accessed $12 / 3 / 2018]$.

WRAP (2018b). Love your clothes. http://www.wrap.org.uk/content/ love-your-clothes-waste-prevention [last accessed 14/3/2018].
WRAP (2018c) Sustainable Clothing Action Plan http://www.wrap.org. uk/sustainable-textiles/scap [last accessed 25-6-2018].

WRAP (2018d). Face-to-face exchange for reuse. http://www.wrap.org. uk/content/face-face-exchange-re-use [last accessed 25-6-2018].

Weber S, Lynes J and Young S.B. (2017). Fashion interest as a driver for consumer textile waste management: reuse, recycle or disposal. Int. J. Cons. Stud., vol. 41 207-215.

Williams I.D. (2015). Forty years of the waste hierarchy. Waste Man. vol. $40,1-2$.

Williams I.D. and Shaw P.J. (2017). Reuse: fashion or future? Waste Man. vol. 40, 1-2

Williams I.D. and Shaw P.J. (2018). Key principles for reuse. Proceedings of SUM2018, Fourth Symposium on Urban Mining, 21-23 May 2018, Bergamo, Italy.

Woolridge A.C., Ward G.D, Phillips P.S., Collins M. and Gandy S. (2006) Life cycle assessment for reuse/recycling of donated waste textiles compared to use of virgin material: an UK energy saving perspective. Resourc. Cons. Recycl., vol. 46, 94-103. 